\title{
Procedimento para coleta dinâmica embarcada de emissões provenientes de veículos transportadores de carga em área urbana
}

\author{
Helry Luvillany Fontenele Dias ${ }^{1}$, Bruno Vieira Bertoncini², Mona Lisa Moura de Oliveira ${ }^{3}$, \\ Francisco Sales Ávila Cavalcante ${ }^{4}$ e Rinaldo dos Santos Araújo ${ }^{5}$
}

\begin{abstract}
Resumo: O presente artigo insere-se no estudo das emissões de poluentes atmosféricos provenientes do tráfego de veículos transportadores de carga em áreas urbanas. A motivação desta pesquisa deve-se ao fato de que as análises de emissões são, geralmente, realizadas de maneira estática, não representando com adequada precisão o comportamento das emissões geradas em um percurso comum. Assim, buscou-se construir um procedimento de coleta de emissões capaz de ser aplicada com o veículo em movimento, considerando as particularidades dos poluentes provenientes de motores ciclo diesel, comumente utilizados em veículos de carga. Para tal, um sistema formado por equipamentos já existentes e outros desenvolvidos na pesquisa foi proposto. Tal sistema é capaz de realizar, de maneira embarcada, a coleta dos poluentes liberados no escapamento enquanto o veículo realiza normalmente sua operação e seus movimentos, sobretudo considerando os principais poluentes advindos de motores a diesel, como NOx e Materiais Particulados. Os dados coletados indicam que a legislação em vigor não está sendo respeitada em termos de Material Particulado, cujo valor coletado está acima da referência.
\end{abstract}

Palavras-chave: Emissões veiculares; veículos de carga; coleta dinâmica.

\begin{abstract}
This article is inserted on the study of emissions of air pollutants from the freight transport vehicles traffic in urban areas. The motivation for this research is due to the fact that the emission analyzes are generally performed in static state, not representing with adequate accuracy the behavior of emissions generated in a common path. Thus, was attempted to build an emission collection procedures that could be applied to the moving vehicle, considering the particularities of pollutants from diesel engines, commonly used in cargo trucks. For such, a system made up of existing equipment and other developed in the research was proposed. Such system is capable of performing, shipped on vehicle, the collection of pollutants released in the exhaust while the vehicle normally carries out its operations and movements, especially considering the major pollutants coming from diesel engines, such as NOx and Particulate Matter. The data collected indicate that the legislation is not being respected in terms of Particulate Matter, whose collected amount is above the reference.
\end{abstract}

Keywords: Vehicle emissions; freight transport; dynamic collection.

\section{INTRODUÇÃO}

Dentre os desafios para as cidades, em termos de mobilidade, está a distribuição da carga urbana. Em vista desta problemática, Taniguchi et al (2001) afirmam que o transporte de carga é responsável por uma série de efeitos nocivos, que acarretam em impactos no tráfego, na infraestrutura, no consumo energético e no ambiente. No entanto, apesar de resultar em efeitos nocivos, os fatores ambientais não são amplamente considerados quando da proposição de políticas públicas que regulamentam a distribuição de carga em áreas urbanas.

Dentre os poluentes atmosféricos emitidos pelos veículos, podem-se citar: óxidos de nitrogênio, compostos orgânicos voláteis e os materiais particulados, associados usualmente a veículos movidos a combustíveis fósseis e que tem efeito nocivo à saúde humana e à qualidade de vida em

\footnotetext{
${ }^{1}$ Helry Luvillany Fontenele Dias, Universidade Federal do Ceará. (harrymax@hotmail.com)

2 Bruno Vieira Bertoncini, Universidade Federal do Ceará.

(bruviber@det.ufc.br)

${ }^{3}$ Mona Lisa Moura de Oliveira, Universidade Estadual do Ceará.

(mona.lisa@uece.br)

${ }^{4}$ Francisco Sales Ávila Cavalcante, Universidade Estadual do Ceará

(sales.avila@uece.br)

${ }^{5}$ Rinaldo dos Santos Araújo, Instituto Federal de Educação do Ceará.

(rinaldo@ifce.edu.br)
}

Manuscrito recebido em : 14/02/2015 e aprovado para publicação em 08/07/2015.

Este artigo é parte de TRANSPORTES v. 23, n. 3, 2015. ISSN: 2237-1346

(online). DOI: 10.14295/transportes.v23i3.888 meios urbanos. No caso dos veículos com motor ciclo diesel, as emissões de tais poluentes são da ordem de 50 a 100 vezes maior que veículos movidos à gasolina. Além das emissões de dióxido de carbono (a rigor não deveria ser considerado um poluente atmosférico) que em altas taxas de emissão podem contribuir para o aumento do aquecimento global, por ser um dos gases responsáveis pelo efeito estufa (GEE), ou seja, seus efeitos adversos tendem a ser globais. As proporções de emissões de cada tipo de veículo automotor são apresentadas na Figura 1.

Os motores de combustão interna, como os costumeiramente empregados para mover os veículos transportadores de carga, têm participação significativa na emissão de vários poluentes, dentre eles, monóxido de carbono (CO), hidrocarbonetos $(\mathrm{HC})$ e óxidos de nitrogênio $\left(\mathrm{NO}_{\mathrm{x}}\right)$. Vale frisar que esses poluentes também são formados em outros processos de combustão (por exemplo, em uma termoelétrica), porém a produção de poluente por unidade de combustível queimado é maior nos motores veiculares. Esta maior produção se deve a vários fatores, a citar: operação sempre com deficiência de oxigênio; combustão não permanente; atomização insuficiente do combustível; e o sistema de refrigeração do motor, que impede a queima por igual da mistura comburente (Lima et al, 2011).

Com o intuito de quantificar dados de emissão de poluentes atmosféricos de cidades brasileiras, Vasconcelos (2012) afirma que na Região Metropolitana de São Paulo a emissão de monóxido de carbono representa $60,8 \%$ do total de emissões de poluentes atmosféricos, acompanhada por óxido de nitrogênio (26,7\%) e material particulado (10,6\%). 


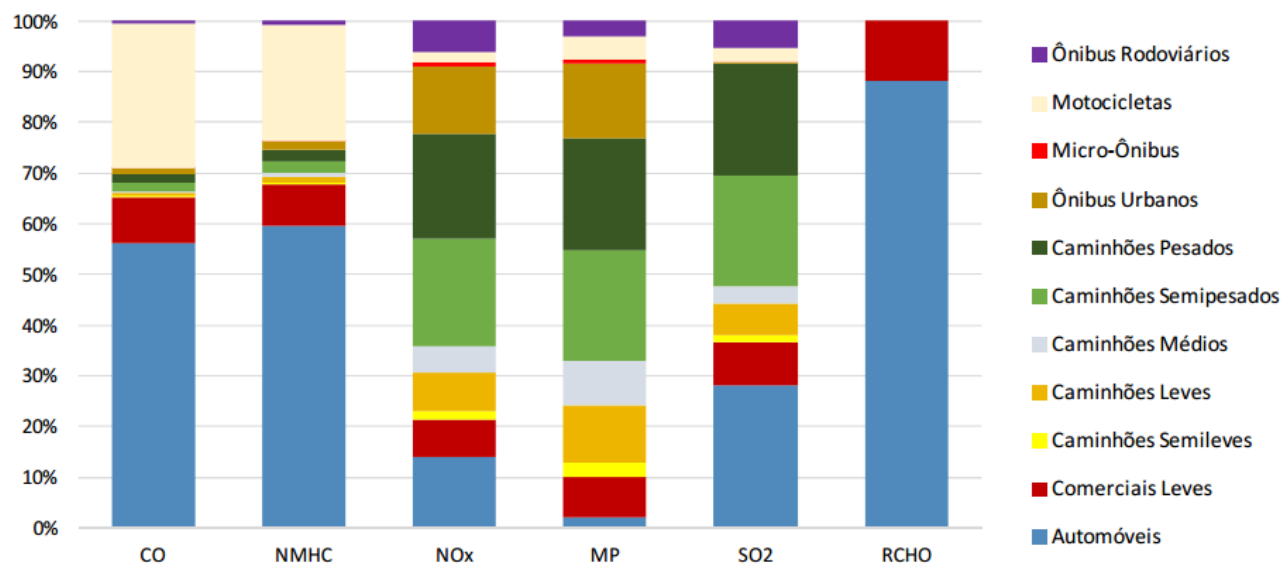

Figura 1. Emissões relativas de poluentes por tipo de fontes - 2005

Fonte: CETESB (2013)

A série histórica de levantamentos realizados entre 1997 e 2003 pela Companhia de Tecnologia e Saneamento Ambiental (CETESB) aponta que o número de dias com concentrações elevadas de material particulado, monóxido de carbono e ozônio está inadequada para os padrões estabelecidos pela Organização Mundial da Saúde (OMS). É importante frisar que mais da metade das taxas de poluição são provenientes do tráfego urbano, estima-se que na cidade do Rio de Janeiro 77\% das emissões sejam advindas da circulação de veículos (COPPE, 2006). Porém tais informações são provenientes de estações de monitoramento distribuídas pelos centros urbanos, não refletindo as emissões em função das condições dinâmicas de tráfego.

A poluição advinda de fontes móveis recebe grande influência da velocidade do tráfego. Velocidades mais baixas tendem a maiores taxas de emissão, embora velocidades muito elevadas também contribuam para aumento das emissões. Centros urbanos adensados tendem a apresentar velocidades muito baixas ao longo dos dias, o que contribui para aumento das emissões. O transporte e distribuição de mercadorias em áreas urbanas torna-se um reflexo desta situação, pois os veículos empregados nesta atividade, por natureza, são mais lentos e realizam muitas manobras de parada e saída. Veículos movidos a diesel são os maiores responsáveis pelas emissões de óxidos de nitrogênio $\left(\mathrm{NO}_{\mathrm{x}}\right)$ e materiais particulados (MP), sendo, em parte, o último consequente da presença de enxofre no diesel, apesar de haver esforços para sua diminuição. Ambos causam efeito local, pois atingem diretamente as pessoas. $\mathrm{O} \mathrm{NO}_{\mathrm{x}}$ causa irritação dos olhos e nariz, dano aos pulmões e estresse do coração, já o MP apresenta toxidade sistêmica, função pulmonar diminuída e estresse do coração. Segundo a OMS(2014), os poluentes atmosféricos foram responsáveis por cerca de 7 milhões de mortes em todo o mundo, por exposição a esses compostos.

É sabido que são poucos os centros urbanos que estudam a distribuição de suas cargas e os efeitos em termos de mobilidade, porém é ínfimo o número dos que buscam avaliar os totais de emissão de poluentes atmosféricos produzidos pelos veículos transportadores de carga. As coletas dos poluentes emitidos a partir da combustão incompleta de motores veiculares são geralmente realizadas com o funcionamento do motor em nível estático, ou seja, com veículo parado, analisando os poluentes em situações mais próximas do ideal. Outra forma é com auxílio de dinamômetros, buscando simular situações reais de uso do veículo, contudo, podendo não representar as condições mais adversas em que o veículo analisado pode ser submetido em seu uso comum.

Em face da problemática apresentada o objetivo deste artigo é propor um procedimento para coleta de emissões com um sistema embarcado, capaz de obter dados dos principais poluentes provenientes de veículos transportadores de carga, com motor ciclo diesel, em áreas urbanas. Em complementação, os objetivos específicos e sua estrutura ao longo do texto são: avaliação dos tipos de coletas de emissões veiculares empregadas e levantamento teóricos de seus impactos (item 2); proposição e detalhamento da metodologia de coleta dinâmica (item 3); aplicação da metodologia de coleta em campo e resultados obtidos (item 4); conclusões (item 5).

\section{IMPACTOS DAS EMISSÕES VEICULARES E TIPOS DE COLETA}

Considerando os impactos avaliados em toda a cadeia produtiva do diesel e seu uso nos transportes de carga em áreas urbanas, Behrends (2011) afirma que os objetivos para se obter um transporte de carga sustentável em meio urbano são: (i) garantir a oferta de acessibilidade pelo sistema de transporte para todas as categorias de transporte de mercadorias; (ii) reduzir a poluição do ar, a emissão de gases de efeito estufa, de resíduos e de ruídos a níveis de baixos impactos negativos sobre a saúde dos cidadãos ou sobre a natureza; (iii) melhorar o consumo energético, em termos de eficiência e eficácia do uso dos recursos, como consumo de combustível, para o transporte de mercadorias, considerando as externalidades; e (iv) contribuir para o reforço da atratividade e da qualidade do ambiente urbano, evitando acidentes, minimizando o uso da terra, sem comprometer a mobilidade dos cidadãos.

Uma maneira de analisar os impactos decorrentes de todo o processo produtivo do diesel que será queimado é por meio da análise do ciclo de vida ( $L C A=$ Life Cycle Assessment), que busca quantificar todo o fluxo de materiais e de energia necessários para a produção do diesel que será utilizado pelos veículos transportadores de carga em área urbana, incluindo a produção, uso e descarte (ou exaustão) do combustível em questão, podendo esta última ser estudada através da metodologia proposta nesta pesquisa. 
Atualmente, muito pouco tem sido feito neste sentindo, as cidades enfrentam dificuldades em relação ao sistema de transporte urbano, no que se refere aos impactos ambientais que os mesmos podem acarretar, sobretudo sob o ponto de vista de emissão de poluentes atmosféricos, no qual está inserido o transporte de cargas e de pessoas. Embora seja igualmente importante no contexto econômico, o enfoque de pesquisas e políticas está direcionado, apenas, para o transporte de passageiros (Lima Júnior, 2003). O transporte urbano de cargas é vital para a economia de uma cidade, pois a disponibilização de matérias-primas e produtos acabados garante a realização de atividades econômicas. $\mathrm{Na}$ atual conjuntura, nenhuma área urbana pode existir sem um robusto, sustentável e confiável fluxo de bens (Ogden, 1992), podendo-se afirmar que a movimentação de cargas é indissociável do modo de vida da sociedade moderna.

Neste contexto, a análise das emissões de poluentes atmosféricos provenientes dos veículos de carga se faz necessário. A técnica mais utilizada para a medição das emissões de poluentes veiculares é o teste dos veículos em laboratório. Este tipo de teste fornece resultados com maior controle das condições do ambiente. Os testes em laboratório são padronizados por órgãos reguladores e podem ser dinâmicos, havendo carregamento no motor através de ciclos de condução em dinamômetros de chassi, ou estáticos, sem carregamento do motor (FAIZ et al., 1996; WENZEL et al., 1998).

No teste estático medem-se as concentrações de poluentes emitidos pelo escapamento de um veículo estacionado em ponto morto. O teste foi proposto, inicialmente pelo Clean Air Act e, no Brasil, foi adotado pelo CONAMA (Conselho Nacional do Meio Ambiente), devido ao baixo custo e rapidez do método, para identificar veículos com padrões irregulares de emissão. Uma variante deste ensaio consiste em testar o veículo em ponto morto e aumentar a rotação do motor até 2500 rpm. O objetivo da alteração na rotação é se aproximar das condições de operação do veículo em condições de carregamento. O teste estático é muito empregado em programas de inspeção veicular e manutenção (BRASIL, 2004).

No caso do teste dinâmico, o veículo é disposto em um dinamômetro de chassi que simula as forças de inércia e atrito que o veículo enfrentaria em uma via comum. O veículo é conduzido por um homem ou uma máquina seguindo o mais próximo possível as velocidades especificadas por um ciclo de condução estabelecido. As emissões podem ser medidas de duas formas durante o teste com dinamômetro de chassi: total gerado durante todo o teste; ou de forma contínua, geralmente, segundo a segundo. A quantificação do combustível evaporado, proveniente de respiros e conexões do sistema de alimentação de combustível, é realizada em uma câmara hermeticamente fechada (MENDES, 2004).

Contudo, mesmo com o uso de dinamômetros, as particularidades de um veículo transportador de carga operando em um ambiente urbano podem não ser representadas adequadamente. Medições a bordo realizadas durante a operação dos veículos permitem a coleta simultânea de velocidade, aceleração (com o auxílio de equipamento de diagnóstico $O B D$, por exemplo) e emissões de veículos a cada segundo em condições reais de operação. As medições dos poluentes atmosféricos são realizadas a partir da coleta dos 20 gases do escapamento e analisadas por um dispositivo portátil adaptado ao tubo de escape dos veículos. Nestes casos, não é necessário modificar o veículo para a instalação do equipamento (ROUPHAIL et al., 2000).

As medições realizadas nos veículos em operação nas vias são conduzidas em um ambiente de condições não controladas, apresentando variabilidade em seus resultados (em função das diferentes condições a que podem estar submetidos, considerando um mesmo trecho de análise). A grande vantagem das medições a bordo do veículo é a representação das emissões em condições realísticas, eliminando a possível falta de representatividade dos ciclos de condução utilizados nos ensaios com dinamômetros de chassi (FREY e UNAL, 2002).

\section{CONSTRUÇÃO DO PROCEDIMENTO DE COLETA DINÂMICA}

O procedimento de coleta proposto no presente trabalho consistiu em embarcar uma aparelhagem no veículo, de forma a possibilitar a coleta de emissões de poluentes atmosféricos gasosos de forma dinâmica. A proposta discutida no presente artigo, por sua vez, permitiu realizar análises instantâneas dos poluentes emitidos, considerando os ensaios realizados na fase P-7 do PROCONVE (Programa de Controle de Poluição do Ar por Veículos Automotores), em que é aplicado o ciclo E.T.C. (Ciclo Europeu em Regime Transiente), cuja análise é realizada a cada segundo. Em complementação, por se tratar de coleta em veículos equipados com motor ciclo diesel, buscou-se, também, coletar materiais particulados, em virtude da grande quantidade deste tipo de poluente desprendida por tais motores. Destaca-se que tais partículas, em sua maioria, são inaláveis-ultrafinas, apresentando potencial de impactos na saúde humana.

Considerando os materiais particulados, a coleta foi realizada utilizando filtros de celulose, capazes de reter partículas com diâmetros até $10 \mu \mathrm{m}$, considerados nocivos à saúde humana e que, também, podem causar danos à infraestrutura urbana (fiação de rede de distribuição de energia elétrica, vias de transporte, monumentos, dentre outros). Partículas entre 5 e $10 \mu \mathrm{m}$ são retidas naturalmente pelo trato respiratório dos seres humanos, porém, em altas concentrações, causam danos à infraestrutura urbana. Já partículas com diâmetro inferior a $5 \mu$ m são capazes de trazer danos a saúde humana. Desta forma, foram projetados e construídos dois equipamentos, do tipo filtrante, de forma a possibilitar a coleta de tais materiais. O primeiro equipamento é um filtro cassete (Figura 2a), cuja função é acomodar uma lâmina filtrante de celulose, cuja função é reter os poluentes. O outro equipamento foi um ciclone (Figura 2b) que permite a realização da separação de partículas, conforme seu diâmetro. Tais equipamentos são utilizados em conjunto, conforme ilustrado na Figura 2c. Apesar de serem comercializados, houve a necessidade de serem projetados e construídos por não possuírem as características necessárias para o experimento em questão.

Além dos equipamentos desenvolvidos, foi empregado no experimento um sistema composto por: um tubo de alumínio para conduzir a vazão do gás; um dispositivo para absorção da umidade; uma bomba de sucção com vazão 


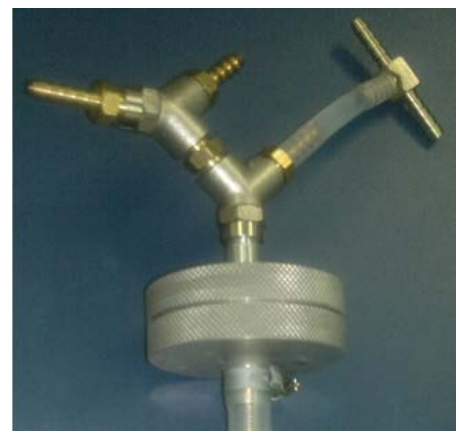

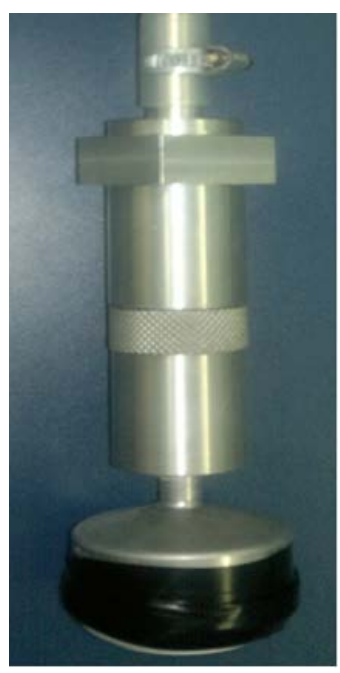

(b)

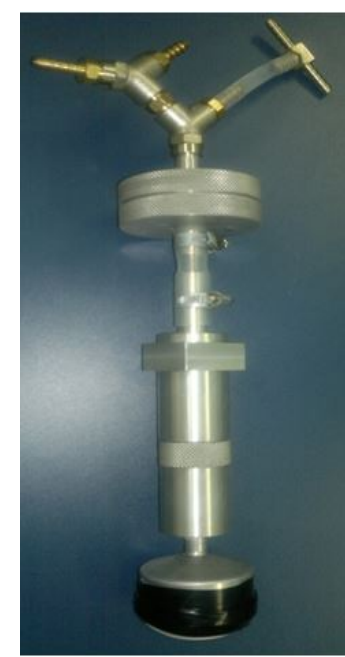

(c)

Figura 2. Equipamentos projetados e construídos para o experimento: (a) cassete (b) ciclone; (c) complexo ciclone + cassete

constante e que atenda as especificidades do conjunto de filtros projetados (no caso foi de aproximadamente 33 $1 /$ min) controlada, de forma a garantir fluxo adequado de gás para o sistema; um contador de partículas capaz de realizar a contagem de partículas de $0.3,0.5,1.0,2.5,5.0$ e 10.0 $\mu \mathrm{m}$ (partículas de $0,3 \mu \mathrm{m}$ com $50 \%$ de precisão; partículas a partir de $0,45 \mu \mathrm{m}$ com $100 \%$ de precisão; um analisador de partículas eletrônico portátil, Greenline 8000, capaz de analisar fluxos dos compostos $\mathrm{O}_{2}, \mathrm{CO}_{2}, \mathrm{CO}, \mathrm{NO}_{\mathrm{x}}, \mathrm{SO}_{2}, \mathrm{H}_{2} \mathrm{~S}$ ou $\mathrm{C}_{\mathrm{x}} \mathrm{H}_{\mathrm{y}}$ (capaz de obter dados de até $20000 \mathrm{ppm}$ de CO, até $4000 \mathrm{ppm}$ de $\mathrm{NO}_{\mathrm{x}}, 0$ a $5 \%$ de $\mathrm{C}_{\mathrm{x}} \mathrm{H}_{\mathrm{y}} \mathrm{v} / \mathrm{v}$, até $4000 \mathrm{ppm}$ de $\mathrm{SO}_{2}$ ).

O sistema precisou foi adaptado para ser adequadamente transportado e não colocar em risco a operação do veículo e o manuseio por parte dos pesquisadores, sendo que há elementos de controle para avaliar a temperatura, vazão da bomba e energização do sistema (feita por meio de um inversor de corrente conectado à bateria do veículo). Assim, construiu-se um equipamento que pode ser facilmente instalado na carroceria do veículo e a conexão com o escapamento é feita por intermédio de um tubo flexível, com comprimento variável, conforme o tipo de veículo testado, no caso particular deste trabalho o tubo tinha extensão de 2,00 metros. Assim, o equipamento proposto é apresentado na Figura 3, sendo que nela são apresentados detalhes do conjunto: (1) tampa superior do equipamento; (2) parte frontal do equipamento e comandos; (3) lateral do equipamento, com destaque para o filtro cassete e o tubo de entrada de gás; (4) parte traseira do equipamento, com destaque para o contador de partículas e o gasômetro. O equipamento proposto no experimento possui peso de aproximadamente 25 kg, com dimensões (400 x 200 x 300 mm, aproximadamente), o que confere vantagem em termos de transporte, acondicionamento e não causa interferência na operação do veículo. A título de comparação, equipamento utilizado no meio técnico (Horiba GS-12) para executar tais medições possui peso $45 \mathrm{~kg}$ e dimensão 460 × 350 × 470 $\mathrm{mm}$. Outro aspecto a ser destacado é que o conjunto proposto possui valor equivalente a aproximadamente $20 \%$ do valor do Horiba GS-12.
Em síntese, os equipamentos constituintes do aparato, para uma dada vazão constante de gás succionado pelo sistema, desempenham a função de separação e condicionamento das partículas com maior potencial de danos a saúde humana, coleta de dados (compostos gasosos) em ppm (partes por milhão) ou em valores percentuais, contagem das partículas de $0,3 \mu \mathrm{m}$ a $10 \mu \mathrm{m}$, em intervalo de tempo prédefinido, o que é importante para entender as proporções de partículas menores até $5 \mu \mathrm{m}$ e sua variação ao longo do percurso/operação.

Posteriormente, fazendo uso de equipamentos laboratoriais é feita uma análise mais detalhada de cada poluente impregnado na lâmina de celulosa acondicionada ao filtro cassete. Em complementação ao equipamento de coleta de emissões, foi utilizado um sistema de diagnóstico tipo OBD, para capturar as informações de desempenho do veículo, e um GPS de precisão, de forma a armazenar as informações da rota desenvolvida. Tal conjunto (OBD + GPS) possibilita gerar o ciclo de condução a cada passagem e realizar o levantamento das velocidades instantâneas, que são imprescindíveis para os cálculos das velocidades médias e cálculo das emissões instantâneas e médias.

\section{APLICAÇÃO DO PROCEDIMENTO DE COLETA E RESULTADOS ALCANÇADOS}

Com o objetivo de analisar a viabilidade do procedimento de coleta de dados de emissão de poluentes atmosféricos, foi considerado o uso de um veículo transportador de carga (VUC) regulamentado para a cidade de Fortaleza (CE). O procedimento de coleta de dados é apresentado a seguir, apresentado o procedimento e critérios de coleta (4.1), a análise laboratorial dos equipamentos (como filtros e demais equipamentos, 4.2) e o tratamento dos dados com a ajuda de equipamento computacional (4.3):

\subsection{Aplicação do Procedimento de Coleta das Emissões}

No estudo foi utilizado caminhão Iveco, modelo 45S14, ano 2007, com peso bruto total (PBT) de $4.400 \mathrm{~kg}$, 


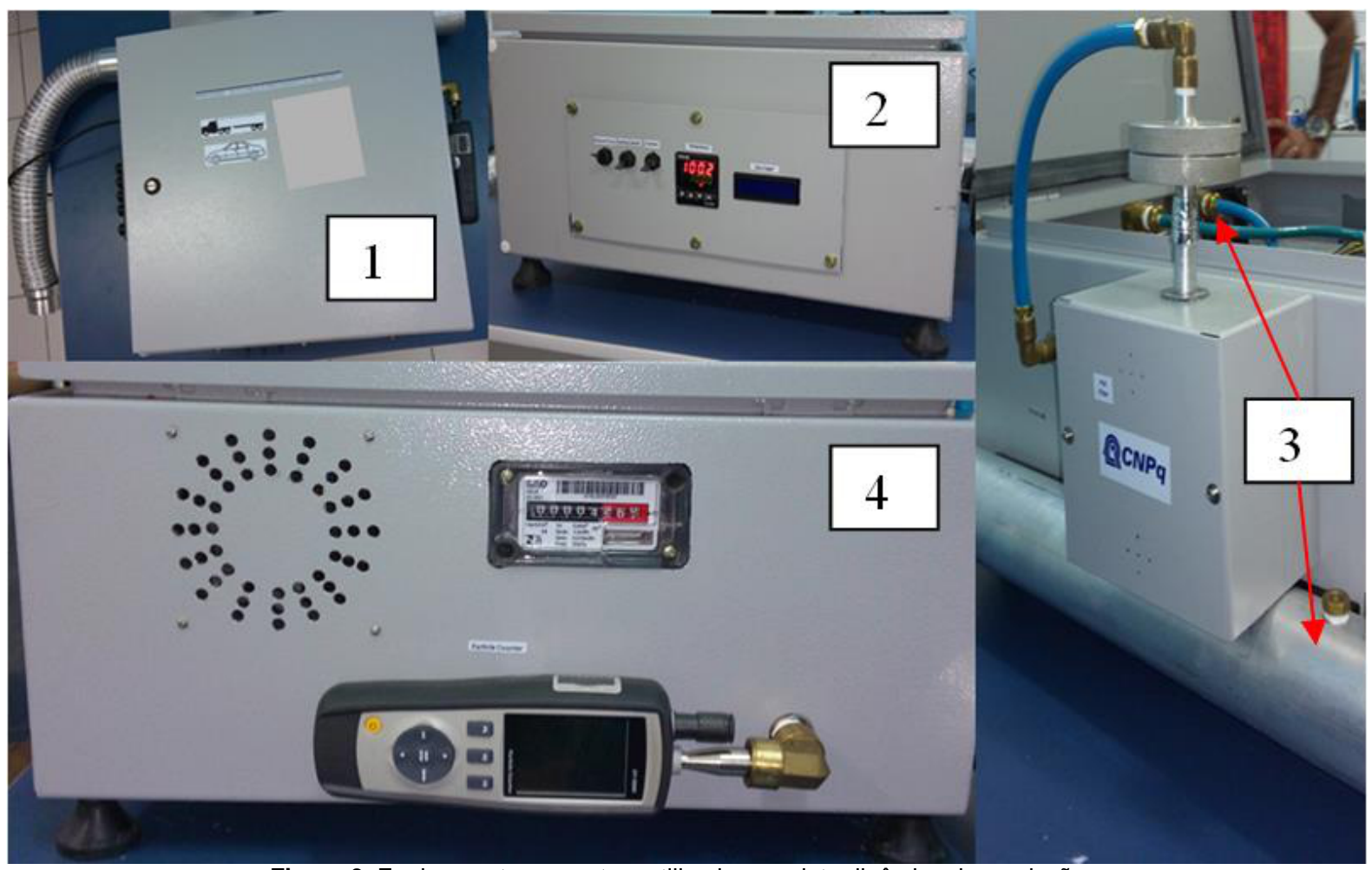

Figura 3. Equipamento proposto e utilizado na coleta dinâmica das emissões.

que se enquadra na categoria intitulada como VUC (Veículo Urbano de Carga). O trecho percorrido, na cidade de Fortaleza, rotineiro na operação diária do veículo, tinha extensão de aproximadamente 530 metros, conforme destacado na Figura 4. O trecho, apesar de pequeno, possui elevada presença de estabelecimentos comerciais e de residências. Observa-se constante fluxo de caminhões que poderiam trazer impactos diretos aos moradores, em termos de emissões. Por fim, devido ao caráter exploratório, decidiu-se manter uma área de controle pequena, em que fosse possível coletar e observar situações cotidianas do tráfego, de forma a possibilitar correlação entre os dados coletados e o tráfego.

A coleta ocorreu no período entre 06:30 h e 09:00 h, em uma terça-feira tendo sido realizadas seis passagens dentro do período estabelecido. Destaca-se que durante o dia de coleta o clima estava típico, sem precipitação chuvosa e temperatura em conformidade com a média local. Após cada passagem, o veículo parava em um estacionamento, para se observar o equipamento, bem como fazer a troca das lâminas de celulose.

\subsection{Análise Laboratorial das Coletas de Emissões}

Após as coletas, os filtros de celulose foram devidamente acondicionados e encaminhados para análise laboratorial. Em laboratório, foram pesados e houve cálculo da diferença de massa entre o filtro, antes e após a coleta, com o objetivo de analisar a massa de particulados retidos nos filtros. As Figuras 5a e 5b apresentam filtros de celulose, isento de contaminantes e após a coleta dos particulados, respectivamente.

Os demais poluentes foram coletados com auxílio do analisador de partículas Greenline 8000. Os dados foram obtidos para cada 10 segundos, em virtude da velocidade ter sido coletada também a cada 10 segundos, o que possibilitou calcular as emissões instantâneas e médias a cada trecho percorrido. Destaca-se que o GPS também fez leitura a cada 10 segundos, permitindo relacionar as emissões e a respectiva posição e velocidade do veículo.

\subsection{Tratamento dos Dados de Emissões Coletados}

Para os cálculos das emissões de particulados foram calculados a quantidade em gramas por segundo de cada faixa de materiais particulados $(0.3 \mu \mathrm{m}$ a $10 \mu \mathrm{m})$. A partir das quantidades em gramas por segundo foi possível calcular as quantidades de particulados em gramas por quilômetro, conhecendo as velocidades do veículo.

Os dados com as emissões globais (para os particulados) foram computados para as seis passagens do veículo. Os dados da primeira passagem são apresentados na Figura 6 .

Os dados das outras 5 passagens realizadas na pesquisa se mostraram semelhantes aos apresentados na Figura 6 , sendo possível representar os experimentos com a figura em questão.

Além dos materiais particulados, foram obtidas informações referentes a emissões de: $\mathrm{CO}, \mathrm{CO}_{2}$ e $\mathrm{NO}_{\mathrm{x}}$. A metodologia aplicada com o uso do analisador de partículas também é capaz de estimar dados de $\mathrm{CH}_{4}$ e $\mathrm{SO}_{2}$, contudo não foi observada presença desses compostos nos dados apresentados pelo analisador Greenline 8000. Tal fato deve-se, provavelmente, ao uso de diesel S10, que apresenta menor teor de enxofre, quando comparado ao diesel S50, por exemplo. Tal constatação é importante, pois comprova a redução do enxofre no diesel comercializado, conforme determinação legal. Os dados obtidos estão apresentados nas Figuras 7a, 7b e 7c referentes à primeira passagem, relativos à Monóxido de Carbono, Dióxido de Carbono e Óxidos de Nitrogênio, respectivamente.

É possível notar que, ao longo do tempo de coleta, existem picos de emissões para os gases analisados, esse 


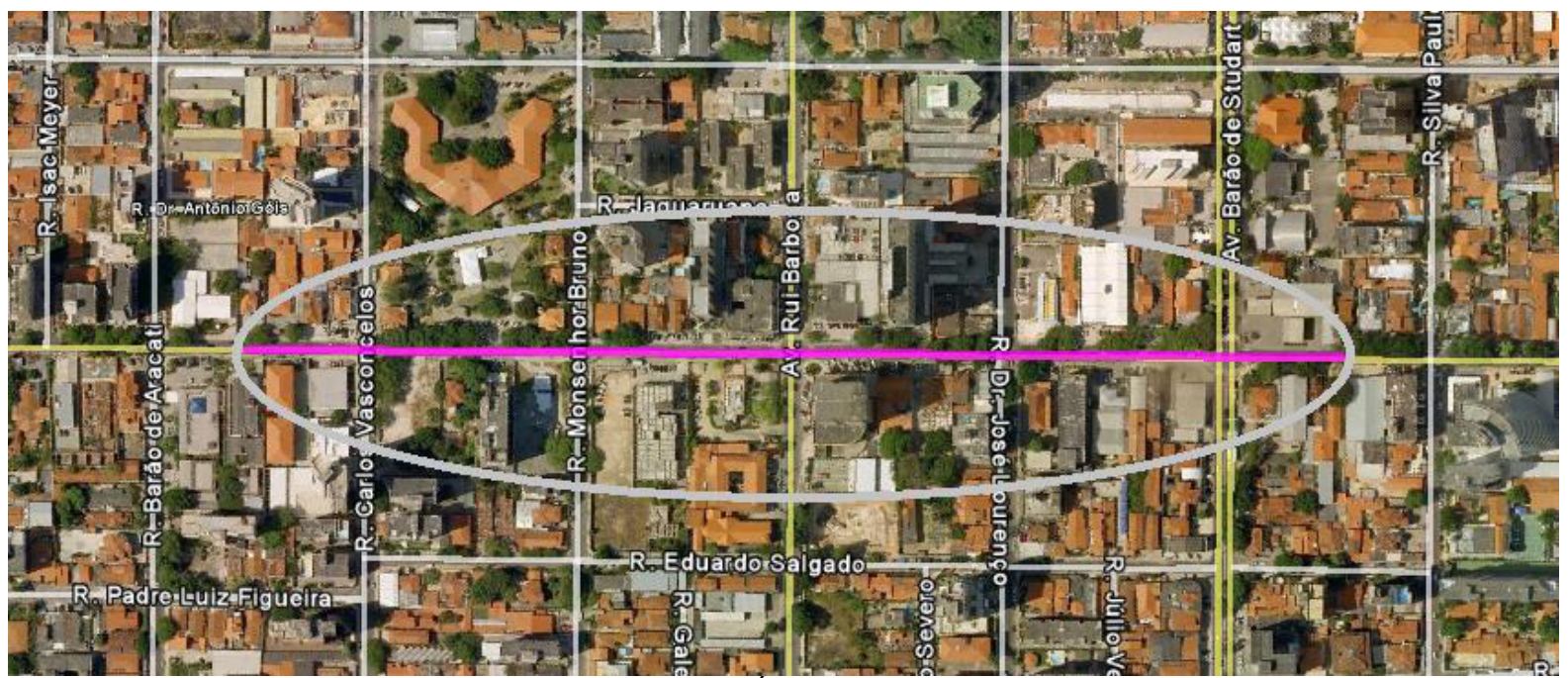

Figura 4. Área de estudo

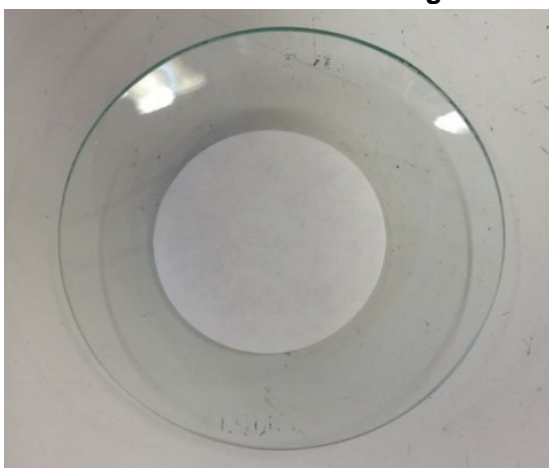

(a)

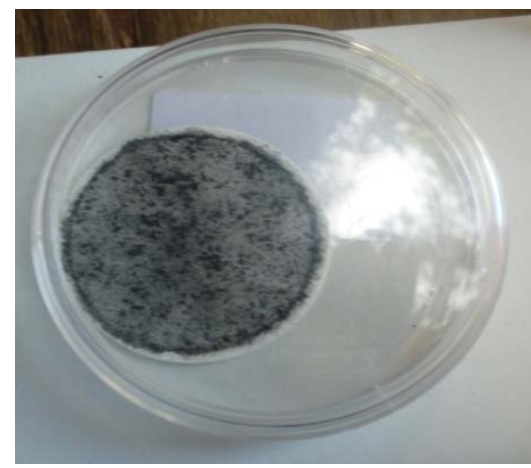

(b)

Figura 5. Imagem de um filtro de celulose sem contaminação (a) e com contaminação (b)

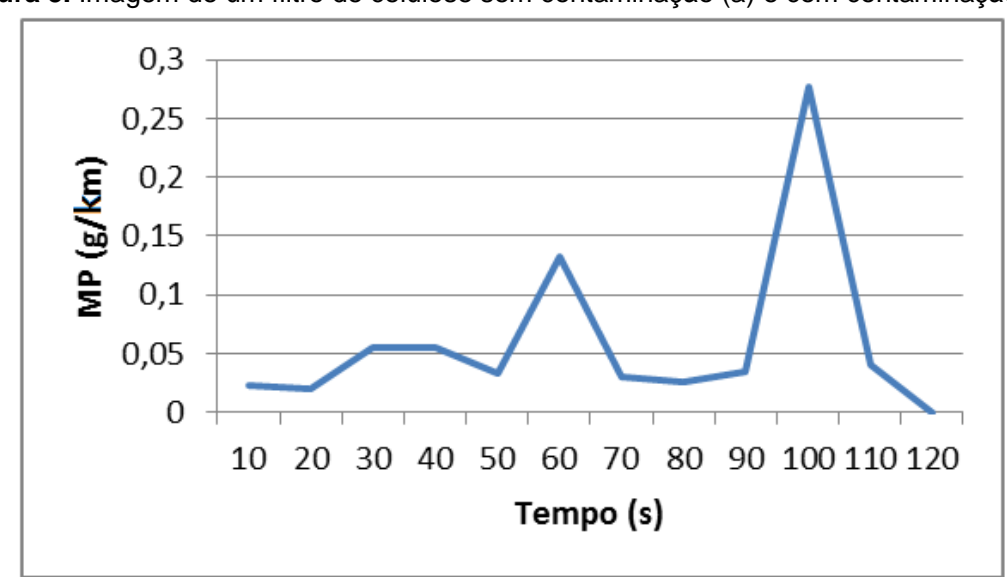

Figura 6. Dados calculados referentes à primeira passagem, 07h08min

comportamento pode ser justificado pelos pontos em que o veículo parava em cada semáforo presente no trecho onde o mesmo trafegava, pois a cada parada o caminhão acelerava com mais força, quando as emissões aumentavam pontualmente nesses momentos, por conta do aumento da rotação do motor.

Para que fossem verificados se os limites estabelecidos pela fase P-7 do PROCONVE estavam sendo obedeias, as emissões foram expressas em gramas por quilowatt-hora. Contudo, os dados coletados foram disponibilizados em ppm (partes por milhão), o que equivale a mg/l.. Conhecendo-se o valor do consumo médio de combustível (expresso em $\mathrm{km} / \mathrm{l}$ ), que no caso do experimento foi de 8,67 $\mathrm{km} / \mathrm{l}$, é possível fazer uma análise dimensional e expressar os valores na unidade estipulada pelo PROCONVE. Tal procedimento é equivalente ao expresso nas Equações (1), (2), (3) e (4).

Emissão * Consumo (convertido em litros por quilômetro) (1):

$$
\left(\frac{m g}{l}\right)\left(\frac{l}{k m}\right)=\frac{m g}{k m} \text { ou } \frac{g}{k m}
$$

Com as emissões em gramas por km, é possível obter os valores em gramas por segundo, conhecendo as velocidades instantâneas:

Emissão * Velocidade (km por segundo) (2):

$$
\left(\frac{g}{k m}\right)\left(\frac{k m}{s}\right)=\frac{g}{s}
$$

Conhecendo o consumo total de combustível em quilogramas por segundo, o calor de combustão do óleo diesel 


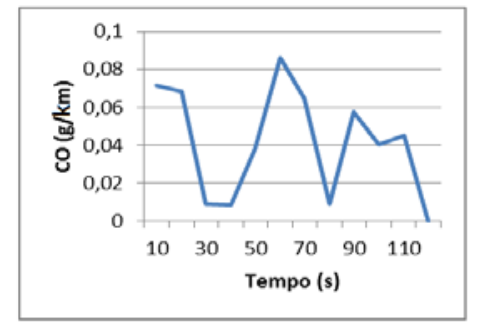

(a)

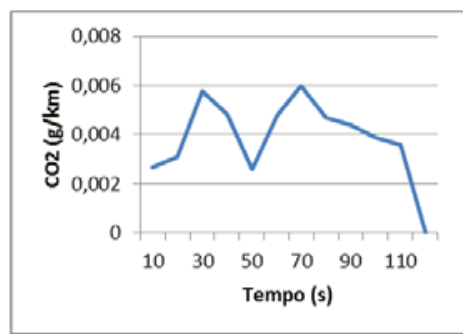

(b)

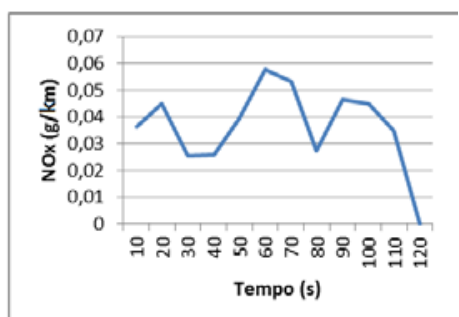

(c)

Figura 7. Dados calculados referentes à primeira passagem, 07h08min

Tabela 1. Dados de emissões obtidos limitados pela fase P-7 do PROCONVE e dados coletados em campo (g/kWh)

\begin{tabular}{lccccccc}
\hline Poluente & $\begin{array}{c}\text { Limites } \\
\text { PROCONVE }\end{array}$ & $\mathbf{1}^{\boldsymbol{a}}$ Passagem & $\mathbf{2}^{\boldsymbol{a}}$ Passagem & $\mathbf{3}^{\boldsymbol{a}}$ Passagem & $\mathbf{4}^{\boldsymbol{a}}$ Passagem & $\mathbf{5}^{\boldsymbol{a}}$ Passagem & $\mathbf{6}^{\boldsymbol{a}}$ Passagem \\
\hline $\mathrm{NO}_{\mathrm{x}}$ & 2.00 & 0,03582758 & 0,03210439 & 0,04787825 & 0,0289390 & 0,0275671 & 0,0281912 \\
$\mathrm{CO}$ & 4.00 & 0,03882438 & 0,01740799 & 0,02455926 & 0,0243288 & 0,0167160 & 0,0154272 \\
$\begin{array}{l}\text { Material } \\
\text { Particulado }\end{array}$ & 0.03 & 0,04481110 & 0,0225877 & 0,0316552 & 0,0411274 & 0,0261095 & 0,0342787 \\
\hline
\end{tabular}

(43 MJ/kg) e o fator de conversão de unidades (wh/MJ = 0,00027) (3):

$$
\left(\frac{k g}{s}\right)\left(\frac{M J}{k g}\right)\left(\frac{W h}{M J}\right)=\frac{W h}{s} \text { ou } \frac{k W h}{s}
$$

Por fim, com a divisão de (2) por (3) obtém-se (4):

$$
\left(\frac{g / s}{k W h / s}\right)=\frac{g}{k W h}
$$

Assim, os valores resultantes da coleta, com a devida conversão de unidades, estão apresentados na Tabela 1, bem como os valores parametrizados pela norma.

Através dos dados coletados em campo, para o trecho analisado, foi possível notar que os limites estabelecidos para os poluentes $\mathrm{NO}_{\mathrm{x}}$ e $\mathrm{CO}$ estão sendo respeitados, quando comparados com a norma PROCONVE. Porém, para Materiais Particulados, quatro das seis análises demonstram que os limites estabelecidos estão sendo ultrapassados. Tal constatação mostra que se faz necessário um estudo mais detalhado, no âmbito das emissões, ao se avaliar intervenções e medidas de circulação de veículos de carga. No caso, o veículo padrão VUC, pode até ter trazido benefícios em termos de trafegabilidade, porém, no que tange a emissões, não está em conformidade com a resolução PROCONVE fase P-7, embora deve-se destacar que a amostra avaliada é pequena. Ainda assim, vale lembrar que os veículos com motor ciclo Diesel são responsáveis por quase a totalidade dos materiais particulados emitidos em área urbana e que tais poluentes são deveras nocivos aos seres humanos, o que reforça a necessidade de uma preocupação maior com tal situação, pois o ganho com a trafegabilidade pode não resultar em ganhos com a qualidade do ar.

Os dados de emissões obtidos podem ser utilizados para análises de um ou mais veículos em meio ao tráfego urbano, considerando suas particularidades. Uma generalização pode ser obtida por meio de modelos matemáticos de emissão, sobretudo os integrados a modelos de tráfego (simuladores). Neste sentido, a metodologia proposta torna-se ferramenta importante para coleta de dados a serem empregados nas etapas de calibração e validação de tais modelos, pois possibilitam fornecer dados reais, obtidos de condições 24 reais de operação, sem interferir no funcionamento do veículo, ou trazer prejuízos para a operação.

\section{CONCLUSÕES}

Esta pesquisa teve por objetivo propor e descrever um procedimento embarcado para coleta de emissão de poluentes provenientes de veículos de carga urbana com motor ciclo diesel, em função das particularidades que apresentadas pelo mesmo. Foram apresentadas as principais características dos materiais que são desprendidos na queima do diesel e coletadas pelo conjunto de equipamentos empregado. Para a construção do procedimento foi embarcado o dispositivo em uma operação rotineira do veículo, tendo sido selecionado uma área onde existisse presença de caminhões e veículos de passeio, bem como a presença de residências, pois o adensamento urbano pode impactar de forma negativa na operação de um veículo transportador de carga.

A proposta apresentada se mostrou capaz de realizar as coletas de Monóxido de Carbono (CO), Dióxido de Carbono $\left(\mathrm{CO}_{2}\right)$, Óxidos de Nitrogênio $\left(\mathrm{NO}_{\mathrm{x}}\right)$ e Materiais Particulados, com o veículo em operação normal, ou seja, uma coleta dinâmica, cujas emissões apresentam um comportamento diferente, quando comparado a análise do motor em laboratório (coleta estática). Ademais, foi capaz de coletar dados relativos a emissões de Dióxido de Enxofre $\left(\mathrm{SO}_{2}\right)$, mas nos levantamentos realizados no estudo, o equipamento não detectou a presença desse composto, em função do diesel com teor de enxofre reduzido, diesel S50 utilizado.

Considerando apenas o experimento realizado na pesquisa, com os dados de emissões coletados e analisados, foi possível verificar que os índices de poluente Monóxido de Carbono e Óxidos de Nitrogênio foram respeitados, quando comparados com as normas vigentes estabelecidas pelo PROCONVE, todavia para os Materiais Particulados os limites não foram respeitados (considerando o veículo e número de observações do universo da amostra), mostrando que medidas de otimização da queima interna do motor dos 
veículos de carga comumente utilizados deve ser considerada, não somente considerando os impactos que esses veículos trazem ao tráfego urbano.

Portanto, o procedimento apresentado pode ser tomado como fonte importante para coleta de informações a serem usadas em atividades de calibração e validação de modelos matemáticos de emissão, o que possibilita generalizações e a observação das emissões provenientes de veículos transportadores de carga em determinada região.

Considerando as limitações apresentadas no estudo realizado, apontam-se algumas sugestões para trabalhos futuros: (i) ampliar o campo amostral de dados de emissões, de forma a ter uma situação mais representativa para a realidade local, o que futuramente poderá contribuir para a calibração de modelos de emissão integrados a simuladores de tráfego, auxiliando na análise ambiental ao se avaliar uma intervenção de transporte; (ii) analisar outros procedimentos para verificação de enxofre, em função de não ter sido detectado na coleta, buscando identificar se o mesmo não está presente na operação de veículos de carga; (iii) analisar as relações entre emissões de poluentes (como Materiais Particulados) e manutenção periódica dos veículos, com vistas a melhoria de eficiência para empresas transportadoras; e (iv) analisar relações entre as emissões coletadas e melhoria de desempenho dos condutores profissionais, visando construir uma política de Eco-driving.

\section{AGRADECIMENTOS}

Os autores agradecem à CAPES pela concessão de bolsas de mestrado e ao CNPq pelo financiamento da pesquisa

\section{REFERÊNCIAS}

Behrends, S., (2011). Urban freight transport sustainability, the interaction of urban freight and intermodal transport.

Department of Technology Management and Economics,

Chalmers University of Technology, Sweden.

Brasil. (2004). Programa de Controle da Poluição do Ar por Veículos Automotores - PROCONVE. Ministério do Meio Ambiente dos Recursos Hídricos e da Amazônia Legal, Instituto Brasileiro do Meio Ambiente e dos Recursos Naturais Renováveis. 2 ed. Coleção Meio Ambiente. Série Diretrizes Gestão Ambiental; n. 2. Brasília. ISBN 85-7300-076-7

COPPE, (2006). “A importância da localização aeroportuária na qualidade do ar - o caso da expansão do aeroporto Santos Dumont na cidade do Rio de Janeiro”.

Faiz, A., C.S. Weaver And M.P. Walsh (1996), “Air Pollution from Motor Vehicles: Standards and Technologies for Controlling Emissions”, World Bank, Washington, D.C. ISBN 08213-3444

Frey, H. C., Unal, A. (2002). Use of On-Board Tailpipe Emissions Measurements for Development of Mobile Source Emissions Factors. International Emission Inventory Conference "Emission Inventories - Partnering for the Future". Atlanta. GA.

Lima, E. P., Demarchi, S. H., Gimenes, M. L., (2011).

Adaptação do modelo de emissão modal CMEM para a frota da cidade de Maringá, Estado do Paraná, Brasil. Universidade Estadual de Maringá. DOI: 10.4025/actascitechnol.v33i1.5118

Mendes, F. E., (2004). Avaliação de Programas de Controle de Poluição Atmosférica por Veículos Leves no Brasil. Tese de Doutorado, COPPE, UFRJ, Rio de Janeiro, RJ. Brasil

Ogden, K. W. (1992) Urban Goods Movement. Ashgate, Hants, England. ISBN 1857420292

Organização Mundial de Saúde (OMS), (2014). Em "Poluição mata mais de 7 milhões de pessoas por ano”. Itir Sonuparlak, TheCityFix.com

Rouphail, N. M., Frey, H. C., Colyar, J. D., Unal, A., (2000). Vehicle Emissions and Traffic Measures: Exploratory Analysis of Field Observations at Signalized Arterials. 80th Annual Meeting of the Transportation Research Board. Washington D.C.

Taniguchi, E., Thompson, R. G., Yamacia, T. E Van Duin, R. (2001) City Logistics - Network Modelling and Intelligent Transport Systems. Elsevier Science, Oxford, UK. ISBN: 9780080439037

Vasconcelos, S. S., (2012). Incêndios florestais e queimadas no amazonas: distribuição, suscetibilidade e emissões de carbono. Instituto Nacional de Pesquisas da Amazônia - INPA

Wenzel, T., And Ross, M., (1998). Characterization of recentmodel high-emitting automobiles. Proceedings of the 1998 SAE International Spring Fuel \& Lubricants Meeting \& Exposition, Dearborn, MI, USA. DOI:10.4271/981414 